\title{
THE IMPORTANCE OF SOCIAL NETWORKS AS A TOOL FOR EMPLOYER BRANDING FROM THE VIEWPOINT OF SLOVAK CONSUMERS
}

\author{
Margareta Nadanyiova ${ }^{1}$ \\ margareta.nadanyiova@fpedas.uniza.sk \\ Veronika Paurova ${ }^{1}$ \\ veronika.paurova@fpedas.uniza.sk \\ ${ }^{1}$ Faculty of Operation and Economics of Transport and Communications \\ University of Zilina \\ 1 Univerzitna, Zilina, Slovak Republic, 01026
}

\begin{abstract}
Social networks are a phenomenon that has become a regular part of life for the majority of consumers and they spend much of free time there. With the increasing popularity of social networks, the possibilities of their use are also expanding. Recently, the trend of social networks has also penetrated into the personnel marketing. Due to the current situation on the labour market, in addition to traditional techniques, companies have begun to use the tools of the social networks to recruit employees and build their employer brands. The aim of this article is to define the theoretical basis of social networks and their usage in employer branding from the viewpoint of domestic (Slovak) and foreign authors. This includes an analysis of the practical usage of social networks in employer branding. The secondary data for the analysis were obtained from annual companies reports, statistical tables and published professional publications. In order to determine the perception of social networks as a tool for employer branding, a questionnaire survey was conducted among Slovak people. General scientific methods were applied for the processing of the data, as well as mathematical methods to evaluate the data, collated from the results of the questionnaire survey. Based on this, benefits of social networks and their usage in employer branding are highlighted.
\end{abstract}

Keywords: social networks, communication, employer branding, personnel marketing, job offer.

DOI: $10.21303 / 2504-5571.2020 .001322$

\section{Introduction}

Currently, social networks are used as a universal communication platform. They represent relatively new and the most popular type of web applications. Social networks offer the possibility of two-way communication with customers and other target groups, help with sales promotion and building the brand [1].

A social network is a virtual space where people meet, create the circle of friends or to join a particular community with common interests [2]. Unlike other media that companies use in their communication, constant contact with target groups is typical for social networks.

Social networks gain more and more attention in the field of personnel marketing and play an important role in the employer branding strategy. Companies realize that on social networks are not only their customers, but also their employees (including potential ones), and thus it is necessary to adapt their communication accordingly. Under current conditions on the labour market, traditional tools for recruiting and reaching employees, such as web job portals, are failing [3]. In this reason, it is necessary to engage and learn to use new resources, the most accessible of which are social networks. Companies, that do not use social networks in employer branding, are becoming less competitive. At the same time, social networks are a user-friendly and cheap tool, through which capable employees can be reliably found. In addition, social networks offer companies the opportunity to raise the visibility of their profile, improve image and strengthen employer brand in the long run.

The issue of the social networks has been researched and analyzed by many foreign and domestic authors, and remains actual.

Scott defined a social network as a platform that allows people to share thoughts and opinions with each other, discuss about Internet content, and make contacts online. Their content can 
be in the form of audio, video, photography, or other visual forms that connect groups and communities, and created as well as commented by any user [4].

According to Janouch, people most often use social networks to communicate with each other. Nevertheless, they can also be used for communication between the company and its target groups [2]. Researches have shown that people perceive social networks not only as a communication tool but also as a source of information [5-8].

According to Bednar, social networks are based on the fact that [9]:

- content is mostly created by the users themselves;

- formed by relationships between users, their comments, links and ratings;

- server operators are only minimally involved in content creation [9].

Ryan and Jones summarized the reasons why it is good for a company to communicate on social networks. They include the deeper relationship with target groups, ability to found out information that is not otherwise obtainable, and the fact they are used by a large number of people [10].

The Italian expert on social media Vincenzo Cosenza is publishing every six months the map of the most popular social networks in the world on his blog. Without a doubt, the most popular social network is Facebook, that has 2,5 billion monthly active users and is still growing mostly in Asia Pacific. His analysis shows that it was the leading social network in 151 out of 167 countries [11]. Facebook as well as LinkedIn, Twitter, Instagram and YouTube are the most used social networks in personnel marketing, including employer branding.

Over the years, several authors have dealt with the social networks and their usage in employer branding. Nayak et al. dealt with the growing utilization of social networking sites as part of the organizational human resources (HR) strategy for employer branding and talent sourcing, acquisition and retention, and reinforcing stronger relationship with their employees [12].

Bondarouk et al. focused their research on detection differences in the opinions of academics and HR professionals on the impact of social media on employer branding. The results of their research shown that the academics see its general effect as the targeting of the audience for recruitment, marketing, company brand, and ways of communication and HR competencies. The practitioners see the image of the employer, visibility of the company, and organization responsiveness [13].

Veiga et al. investigated whether having a job-dedicated page on social media sites is related to a company's employer reputation, and whether it is merely the fact of having a job-dedicated social media page, or actually communicating on that page that is related to a company's employer reputation (as well as an employer brand). Surprisingly, unlike some others researches, they found out that having a job-dedicated LinkedIn page was positively related to employer reputation, whereas having a job-dedicated Facebook or Twitter page was not related to employer reputation [14].

Similarly, Costa-Sanchez and Corbacho-Valencia characterized LinkedIn as a tool of interest for search of employment professionals and useful channel to attract talent. They presented the use of LinkedIn as a tool of business communication, offered a new methodology and provide with a series of recommendations to be applied by corporations [15].

The article is aimed to define the theoretical basis of the social networks and their usage in employer branding from the viewpoint of domestic (Slovak) and foreign authors. This includes an analysis of the practical usage of social networks in employer branding. In order to determine the perception of social networks as a tool for employer branding, a questionnaire survey was conducted among Slovak people. Based on this, benefits of social networks and their usage in employer branding are highlighted.

\section{Materials and Methods}

The aim of this article is to determine the importance of social networks as a tool for employer branding from the viewpoint of Slovak consumers. This includes a literature review on the issue from the perspective of both domestic (Slovak) and foreign authors. By using methods of description, comparison, deduction, induction, it discusses the essence of social networks as well as their usage in employer branding, and also analyses their usage as a tool for employer branding in 
practice. Based on the analysis and the results of the marketing survey, benefits of social networks and their usage in employer branding are highlighted.

The secondary data for the analysis were obtained from annual companies reports, statistical tables and published professional publications - both in print and electronic media. In order to determine the perception of social networks as a tool for employer branding, a questionnaire survey was conducted among Slovak people. General scientific methods were applied for the processing of the data, as well as mathematical methods to evaluate the data, collated from the results of the questionnaire survey. When examining and identifying the utilization of the social networks and their usage in employer branding, the definitions of the approaches and concepts that are mentioned above were maintained.

The aim of the questionnaire survey - both electronic and personal - was to analyse the perception of social networks as a tool for employer branding by Slovak people. The sample size was determined, using the Sample Size Calculator that forms part of Creative Research Systems' survey software and which is provided as a public service. The calculator determines how many respondents need to be interviewed in order to get results that reflect the target population as precisely as possible. This is necessary to avoid any distortion in the survey information. The process requires a base file to work from, which in this case consisted of number of job seekers (1,050 persons) in an unnamed Slovak recruitment agency (wanted to remain anonymous). The confidence interval was set at $5 \%$, with a confidence level of $95 \%$. This means that for the questionnaire survey a $5 \%$ margin of error is assumed. The sample size, calculated by the calculator, was determined to be 281 respondents. In total, 320 respondents participated in the questionnaire survey. The questionnaire survey was conducted during the second half of 2019. The selection of the respondents in the sample set took place at random. The quantitative assessment method was applied to the processing of the information, obtained from the questionnaire survey. The data were processed empirically in the form of percentages, with additional written comments and comparisons.

\section{Results}

Of the 320 respondents in the sample set, 166 (52\%) were female and 154 (48\%) male.

In terms of the age, we identified five categories of respondents:

- respondents aged $18-25$ (26\%);

- respondents aged $26-35(46 \%)$;

- respondents aged 36-45 (22\%);

- respondents aged 46-55 (5\%);

- respondents aged 56 and more (1\%).

The most of respondents (47\%) had a university degree, $32 \%$ secondary education, $19 \%$ basic education and only $2 \%$ had no education.

The results of the questionnaire survey revealed that the majority $(95 \%)$ visit the social networks. The social network Facebook was marked as the most visited (85\%), then LinkedIn (56\%), YouTube (51\%), Instagram (48\%). Twitter was the least popular with respondents (only $7 \%$ ). Respondents, who do not use social networks, belong in the age category 56 and older.

As part of the research, we interested in how experiences have respondents with finding work on social networks. $46 \%$ respondents answered that they had ever been contacted by a recruiter via a social network with a job offer. $50 \%$ respondents stated that they were actively searching for (or have searched in the past) job offers on social networks, mostly LinkedIn and Facebook.

The respondents clearly identified the most interesting forms of job offers on social networks, such as job advertisements in the form of short and concise texts, direct job offers in the form of a private message from the company or recruiter, job advertisements in the form of a combination of graphic visuals or photographs and texts, recruitment video.

From the results of the questionnaire survey it is also clear, that $56 \%$ respondents had already expressed interest at least once by sending a CV or contacting the company for a job offer, published on the social network. However, only $11 \%$ respondents found employment in this way.

The results also show, that job offers on social networks are welcomed by jobseekers. $53 \%$ respondents consider offers on social networks to be an easy way to learn about interesting 
job opportunities, but $38 \%$ of respondents prefer job offers only on social networks, designed for this purpose (e. g. LinkedIn). Only $4 \%$ respondents indicated job offers on social networks as annoying.

Almost half of respondents (47\%) stated they searched for the company's profile on social networks before sending a CV to it or going for an interview. They specified, what kind of information they sought for the potential employer, or about the job broker:

- image of the company, its atmosphere and culture (45\%);

- company headquarters, office, working environment (33\%);

- working team, potential colleagues (21\%);

- mission and vision of the company, subject of activity $(15 \%)$;

- reviews, ratings from social network users (12\%);

- activity, type of shared content, contributions, way of presentation and communication (12\%);

- company website (8\%).

When investigating how important is the quality of a potential employer presentation on social network, $49 \%$ respondents indicated the quality presentation of the employer on social networks to be important and only for $2 \%$ is it not important at all.

The importance of building an employer's brand on social networks is further underlined by the fact that a relatively high percentage of respondents (38\%) stated that they have ever been so much interested in content, shared by companies on social networks, that it was a significant impulse for them to apply for a job there.

\section{Discussion}

From the results of the questionnaire survey it is clear, that job seekers attach considerable importance to social networks when looking for job and finding information about a potential employer. Job seekers consider social networks to be a regular source of job offers as well as a tool for building the employer's brand.

Many authors, who focus on the issue of social networks in the field of personnel marketing, are agree with the mentioned above. However, unlike previous research by other authors $[14,15]$ that has recommended the LinkedIn social network when recruiting employees and highlighted its positive effects on building an employer's brand, our research has shown that job seekers prefer the social network Facebook in the same way. There can be several reasons. One is that Facebook, which is still the world's most popular social network, users log in up to an average of eight times a day and spend an average of 35 minutes online. Companies logically feel the potential for reaching and gaining not only new customers, but also employees. On the other hand, currently, it is possible to find more than 60 million company profiles on Facebook, which signals that the competition is great. Thus, it is not so easy to attract employees, and social marketing requires a well-developed strategy.

Based on the results of the questionnaire survey, benefits of social networks and their usage in employer branding are highlighted, that includes:

- company presentation;

- spreading awareness of the company;

- raising the visibility of a company's profile;

- improving a company's image;

- building an employer brand and increasing its value;

- reaching a larger number of potential job seekers;

- an affordable, cheap and fast variant of advertising;

- recommendations for candidates from acquaintances and friends;

- more flexible and easier communication.

\section{Conclusions}

The issue of social networks and their usage in employer branding has the potential for deeper research in the future - both qualitatively and quantitatively. To obtain statistical relevance, it would be appropriate to investigate the findings of qualitative research quantitatively. A further 
qualitative investigation would be appropriate for expanding knowledge and comparing the usage of particular social networks on building an employer's brand, possibly exploring the usage of social networks on building an employer's brand in the perspective of particular job seekers generations and their comparison.

\section{Acknowledgments}

This paper is an outcome of the science project APVV-15-0505: Integrated model of management support for building and managing the brand value in the specific conditions of the Slovak Republic.

\section{References}

[1] Moravcikova, D. (2018). Generation Y - a mirrors of social media and brands as a reflection in psychographic segmentation. Digital Mirrors, 409-419.

[2] Janouch, V. (2010). Internet marketing. Promote on the web and social networks. Brno: Computer Press.

[3] Hitka, M., Rozsa, Z., Potkany, M., Lizbetinova, L. (2019). Factors forming employee motivation influenced by regional and age-related differences. Journal of Business Economics and Management, 20 (4), 674-693. doi: http://doi.org/10.3846/ jbem.2019.6586

[4] Scott, D. (2007). The New Rules of Marketing and PR. John Wiley \& Sons.

[5] Gajanova, L., Kramarova, K. (2016). Online Marketing Trends in the Slovak Republic. Proceedings of the International Conference on Humanity and Social Science (EBMEI-HSS 2016) - Lecture Notes in Management Science, 63, 68-73.

[6] Moravcikova, D., Kliestikova, J. (2017). Brand Building with Using Phygital Marketing Communication. Journal of Economics, Business and Management, 5 (3), 148-153. doi: http://doi.org/10.18178/joebm.2017.5.3.503

[7] Hitka, M., Lorincova, S., Lizbetinova, L. (2017). Comparison of Using Social Networks for Seeking Employment in Italy and Slovakia. Vision 2020: Sustaiable Economic Development, Innovation Management, and Global Growth, 1579-1586.

[8] Kicova, E., Bartosova, V., Moravcikova, D. (2018). SEO as a Powerful Brand Building Tool in Online Environment. Proceedings of 8th ESE International Conference on Sports, Health and Management (ESE-SHM 2018) - Lecture Notes in Management Science, 91, 210-214.

[9] Bednar, V. (2011). Social media marketing: Assert on Facebook and Twitter. Brno: Computer Press.

[10] Ryan, D., Jones, C. (2009). Understanding digital marketing: Marketing strategies for engaging the digital generation. London: Kogan Page Limited, 304.

[11] World Map of Social Networks. Vincos Blog. Available at: https://vincos.it/world-map-of-social-networks/ Last accessed: 15.04.2020

[12] Nayak, S., Bhatnagar, J., Budhwar, P. (2017). Leveraging Social Networking for Talent Management: An Exploratory Study of Indian Firms. Thunderbird International Business Review, 60 (1), 21-37. doi: http://doi.org/10.1002/tie.21911

[13] Bondarouk, T., Ruel, H., Axinia, E., Arama, R.; Bondarouk, T., Olivas Lujan, M. R. (Eds.) (2013). What Is the Future of Employer Branding through Social Media? Results of the Delphi Study into the Perceptions of HR Professionals and Academics. Advanced Series in Management: Social Media in Human Resources Management. Emerald Group Publishing Ltd., $23-57$. doi: http://doi.org/10.1108/s1877-6361(2013)0000012006

[14] Veiga, S. P. D., Clark, B. B., Moake, T. R. (2019). Influence of Job-Dedicated Social Media on Employer Reputation. Corporate Reputation Review. doi: http://doi.org/10.1057/s41299-019-00083-Z

[15] Costa-Sanchez, C., Corbacho-Valencia, J. M. (2005). LinkedIn for selection and capturing talent. Analysis of LinkedIn usage as employer branding tool. Prisma Social, 14, 187-221. 